\title{
Economics of environmental policy in Turkey: A general equilibrium investigation of the economic evaluation of sectoral emission reduction policies for climate change
}

\author{
Çağatay Telli a , Ebru Voyvoda ${ }^{\mathrm{b}, *}$, Erinç Yeldan ${ }^{\mathrm{c}, \mathrm{d}}$ \\ a State Planning Organization, Turkey \\ ${ }^{\mathrm{b}}$ Department of Economics, Middle East Technical University, Turkey \\ ${ }^{\mathrm{c}}$ Bilkent University, Turkey \\ ${ }^{\mathrm{d}}$ University of Massachusetts, Amherst, United States
}

Received 1 October 2006; received in revised form 1 February 2007; accepted 1 March 2007

Available online 7 May 2007

\begin{abstract}
Research on climate change has intensified on a global scale as evidence on the costs of global warming continues to accumulate. Confronted with such evidence, the European Union set in late 2006 an ambitious target to reduce its greenhouse gas emissions, by 2020, to $20 \%$ below the level of 1990; and invited the rest of the developed economies and the developing world to take part with the Kyoto Protocol. Turkey is the only country that appears in the Annex-I list of the United Nations' Rio Summit and yet an official target for $\mathrm{CO}_{2}$ emission reductions has still not been established. Thus, as part of its accession negotiations with the EU, Turkey will likely to face significant pressures to introduce its national plan on climate change along with specific emission targets and the associated abatement policies.

Given this motivation, we utilize a computable general equilibrium model for Turkey to study the economic impacts of the intended policy scenarios of compliance with the Kyoto Protocol and we report on the general equilibrium effects of various possible environmental abatement policies in Turkey over the period 2006-2020. The model is in the Walrasian tradition with 10 production sectors and a government operating within an open macroeconomy environment. It accommodates flexible production functions, imperfect substitution in trade and open unemployment. We focus on $\mathrm{CO}_{2}$ emissions and distinguish various basic sources of gaseous pollution in the model. Our results suggest that the burden of imposing emission control
\end{abstract}

\footnotetext{
is The views and policy recommendations expressed in the paper are solely those of the authors' and by no means reflect the institutions and the governing bodies stated above. All usual caveats apply.

* Corresponding author. Tel.: +90312210 2056.

E-mail addresses: ctelli@dpt.gov.tr (Ç. Telli), voyvoda@metu.edu.tr (E. Voyvoda), yeldane@bilkent.edu.tr, eyeldan@peri.umass.edu (E. Yeldan).
} 
targets and the implied abatement costs could be quite high, and that there is a need to finance the expanded abatement investments from scarce domestic resources. Policies for environmental abatement via carbon and/or increased energy taxes further suffer from very adverse employment effects. This suggests that a first-best policy would necessarily call for a simultaneous reduction on the existing tax burden on producers elsewhere together with introduction of environmental taxes.

(C) 2007 Society for Policy Modeling. Published by Elsevier Inc. All rights reserved.

JEL classification: C68; H23; Q58

Keywords: Environmental policy; General equilibrium; Climate change; Global warming

Research on climate change has intensified on a global scale as evidence on the costs of global warming continues to accumulate. A special report that appeared in the Financial Times (31 October 2006), for instance, underlines that "releasing 550 parts per million (ppm) of $\mathrm{CO}_{2}$ in the earth's atmosphere would incur a high probability of raising global temperatures by more than $2{ }^{\circ} \mathrm{C}$ above the pre-industrial levels", an upper limit which is regarded as the safety zone for our planet's climate. The analytics of costs and benefits of possible effective action to curb climate change have been tackled, in turn, in a recent well-celebrated report by Sir Nicholas Stern. ${ }^{1}$ The Stern report argued that efforts to stabilize greenhouse concentrations at between 450 and $550 \mathrm{ppm}$ by 2050 would incur a one-off cost of only $1 \%$ of global economic output (equivalent to 2006 US\$ 651 billion). It also warned that, failure to take immediate action would risk the future of the global economy by shrinking the world output by as much as 5-20 percent over the next two centuries. This cost would be due to the likely disruptions to the working people's productivity, due to widespread of new forms of bacteria and loss of amenities.

It was mainly in response to this evidence that in late 2006 the European Union set, what can be called as the most ambitious goal for impeding climate change, cutting its greenhouse gas emissions, by 2020 , to $20 \%$ below the level of 1990 . The EU further announced plans to go further and declared that it would raise its targets to $30 \%$ below the 1990 levels by 2020 to encourage the rest of the developed economies and the developing world to take part with the Kyoto Protocol.

Against this background, Turkish environmental policy is at a crossroad. As part of its bid for full membership in the European Union, Turkey is under significant pressure to comply with the Kyoto Protocol, and to constrain its $\mathrm{CO}_{2}$ emissions and other gaseous pollutants over the next 6 years. Yet, as a newly emerging, developing market economy, Turkey has not yet achieved stability in its energy utilization and gaseous emissions either as a ratio to its GDP or in per capita terms. Turkey is among the 25 countries with the fastest rate of growth in industrial use of energy sources (OECD, 2004). Turkish Statistical Institute (TURKSTAT) data indicate, for instance, that on a per capita basis, consumption of electrical power in Turkey has increased by 6-fold from 1980 to 2005 . TURKSTAT estimates that aggregate $\mathrm{CO}_{2}$ emissions from fossil fuel at $223.4 \mathrm{Gg}$ as of 2004, and will reach $343 \mathrm{Gg}$ by 2010 and to $615 \mathrm{Gg}$ by 2020 . This suggests a secular rise of the ratio of the total $\mathrm{CO}_{2}$ emissions to GDP from 0.632 million tonnes/billion TRY in 2005 to 0.689 million tonnes/billion TRY in 2020.

Under these uncertainties, Turkey's global standing in terms of its international abatement requirements is also a matter of controversy, as it is the only country that appears in the so-called Annex-I list of the Rio Summit of the United Nations and yet an official target for $\mathrm{CO}_{2}$ emission

\footnotetext{
1 "The Economics of Climate Change" available on line at: http://www.hm-treasury.gov.uk.
} 
reductions has still not been established. Thus, as part of its accession negotiations with the EU, Turkey will likely to face significant pressure to introduce its national plan on climate change along with specific emission targets and the associated abatement policies.

The current arsenal of Turkish environmental policy instruments is mostly limited to energy taxes, environmental impact assessments, and pollution penalties. Yet, it is a clearly recognized fact that these instruments will not suffice under a more active environmental policy design and will need to be expanded to include other forms of policy measures such as additional pollution taxes, emission trading and permits, and abatement investments towards reduced energy intensities. However, given the current lack of an adequate quantitative modeling paradigm for environmental policy analysis in Turkey, the effectiveness of such policy interventions and their economic impacts are not obvious and hence the need for the construction and utilization of policy simulation models for environmental policy analysis. ${ }^{2}$

This paper fills this gap and aims to guide policy makers to respond with additional measures that may include broad, market-based incentives designed to accelerate technology development and deployment in Turkey. Its main policy objective is to enable Turkey to integrate sustainable development principles into national development planning and implementation of environmental policy objectives both at the macroeconomic and sectoral levels. To this end, we build a dynamic, multi-sectoral macroeconomic model in the tradition of computable general equilibrium (CGE) paradigm to study issues of environmental and macroeconomic policy interactions over both the commodity and the factor markets, and the impact of various policies on the environment and on greenhouse gas abatement.

We organize the paper under five sections. First, we introduce and provide an analytical evaluation of the key environmental indicators and the energy intensity of the Turkish economy in the medium/long run. We describe the analytical model in Section 2. In Section 3, we utilize the model to develop a "base-run" against which alternative policy scenarios can be contrasted, while in Section 4 we utilize the CGE apparatus as a laboratory device and study the general equilibrium effects of various possible environmental abatement policies. We conclude in Section 5 .

\section{Macroeconomics of environmental policy in Turkey}

\subsection{Towards Kyoto}

Increased awareness on the threat of global warming and climate change has intensified in late 1980s. Given strong evidence that a major source of global warming was increased gaseous pollution $\left(\mathrm{CO}_{2}\right.$ emissions, in particular), the initial response was the adoption of the United Nations Framework Convention on Climate Change (UNFCCC) which was issued at the Rio Summit of 1992. Under the UNFCCC the so-called Annex-I countries committed, on a voluntary basis, to limit their gaseous emissions to 1990 levels. The OECD (1992) and EU countries further joined to form the Annex-II bloc and agreed to provide technical and financial assistance to those countries that remained outside the Annex-I to aid their environmental policies to reduce greenhouse gas (GHG) emissions.

\footnotetext{
${ }^{2}$ Building models for environmental policy analysis, although scarce for Turkey, is quite a common application in literature. Goulder and Pizer (2006) provide a brief survey of research on economics of climate change, including theoretical insights and empirical findings to offer guidance to policy makers. Adkins and Garbaccio (1999) give a bibliography of only computable general equilibrium model applications to environmental issues.
} 
Table 1

Commitments of the EU countries under the burden sharing agreement of the Kyoto Protocol

\begin{tabular}{lccc}
\hline Country & $\begin{array}{l}\text { Target } \\
(\%)\end{array}$ & $\begin{array}{l}\mathrm{CO}_{2} \text { equivalent of } 1990 \text { emissions } \\
\text { (million tonnes) }\end{array}$ & $\begin{array}{c}\mathrm{CO}_{2} \text { equivalent of target emissions } \\
\text { for 2008-2012 (million tonnes) }\end{array}$ \\
\hline Germany & -21 & 1208 & 955 \\
Austria & -13 & 78 & 68 \\
Belgium & -7 & 139 & 129 \\
United Kingdom & -12.5 & 790 & 691 \\
Denmark & -21 & 72 & 57 \\
Finland & 0 & 65 & 65 \\
France & 0 & 546 & 546 \\
Holland & -6 & 217 & 204 \\
Ireland & 13 & 57 & 64 \\
Spain & 15 & 602 & 348 \\
Sweden & 4 & 66 & 68 \\
Italy & -6.5 & 14 & 507 \\
Luxemburg & -28 & 69 & 10 \\
Portugal & 27 & 99 & 87 \\
Greece & 25 & 4264 & 392 \\
Total & -8 & & 3922 \\
\hline
\end{tabular}

Source: International Energy Agency (2005).

Based on voluntary participation, the specific economic and political components of such commitments of the Convention remained ambiguous. ${ }^{3}$ This led to culmination of efforts towards binding commitments as signed in the Kyoto Protocol in December 1997. Accordingly, the AnnexI countries agreed to reduce, on average, their gaseous emissions by $5.2 \%$ relative to 1990 levels over the period, 2008-2012. The transition economies, however, were granted the exception of establishing a different base period (rather than 1990) given their special circumstances ${ }^{4}$ (see Table 1 on the commitment of the EU countries under the "Burden Sharing" Agreement of the Kyoto Protocol).

Turkey, being a member of the OECD, was initially listed in both Annexes-I and II of the UNFCCC, 1992. However, claiming for its special circumstances, it declined to be a participant to the Convention. During the 7th Conference of Parties held in Marrakech in 2001 Turkey was granted its omission from the Annex-II, and its "special circumstances" was recognized as an Annex-I country. Turkey has signed the UNFCCC as the 189th participant on 24 May 2004. Yet, currently Turkey does not have any emission targets, and has not been a party to the Kyoto Protocol.

\subsection{Key environmental indicators of Turkey}

In this paper, we focus mainly on $\mathrm{CO}_{2}$ emissions as the key indicator of environmental pollution. Turkey displays a mid-score in its emission coefficients in comparison to the world and the OECD averages. By 2002, with a per capita $\mathrm{CO}_{2}$ emissions of 2.8 tonnes, Turkey lies significantly below

\footnotetext{
3 See http://www.unfecc.de for a full discussion of the UNFCCC and the Kyoto Protocol.

4 The Kyoto Protocol further recognized the system of Flexibility Mechanisms composed of Joint Implementation, Clean Development Mechanism, and Emission Trading. The emission trading mechanism recognizes the allowance for trading the national emission to meet aggregate national quantitative targets. I
} 


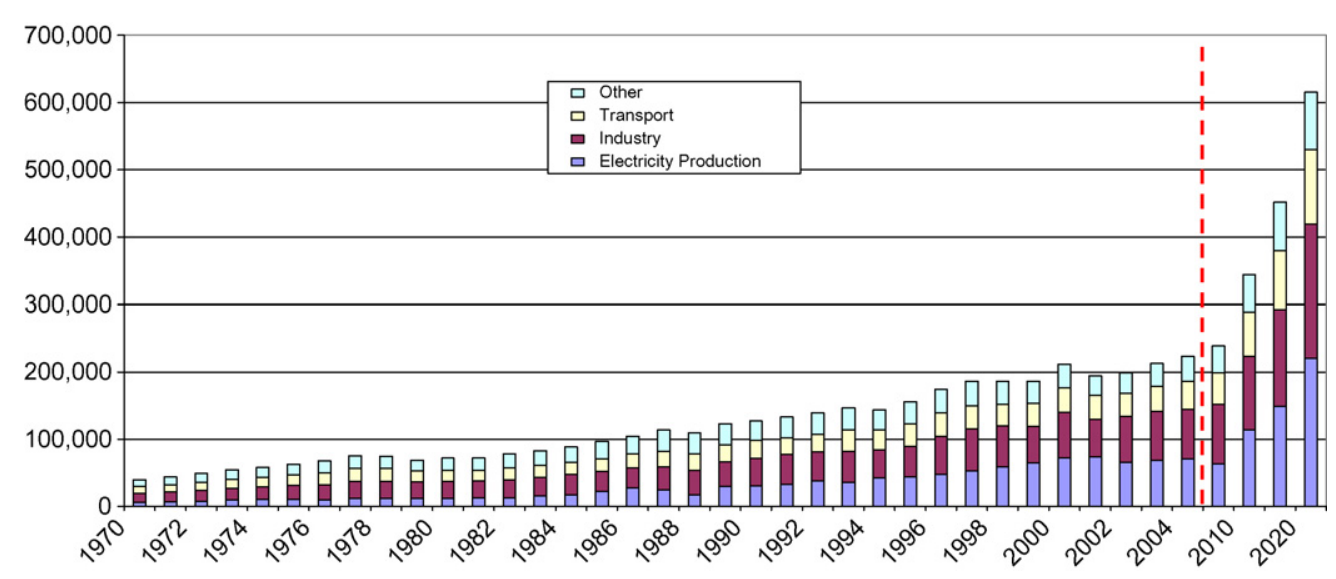

Fig. 1. Sectoral $\mathrm{CO}_{2}$ emissions (Gg). Source: TURKSTAT and MoEF (2006).

the OECD average of 11.0 tonnes and ranks below the world average of 3.9 tonnes per capita. In 1990 these values were, 2.3 tonnes for Turkey, 10.6 tonnes for the OECD and 4.0 tonnes for the world, respectively.

Turkish emissions are less robust when the comparison is done with respect to per US\$ GDP. In 2002 Turkish $\mathrm{CO}_{2}$ emissions per US\$ GDP (measured in fixed 1995 prices) was $0.94 \mathrm{~kg}$. The same ratio was 0.44 for the OECD and the world average was 0.68. As compared to the 1990 values, both the world and the OECD averages on $\mathrm{CO}_{2}$ emissions per US\$ GDP were observed to fall, and for Turkey there had been a slight increase from 0.89 to 0.94 . In Fig. 1, we provide a sectoral breakdown of the aggregate $\mathrm{CO}_{2}$ emissions.

The TURKSTAT data indicate that aggregate $\mathrm{CO}_{2}$ emissions from fossil burning stand at $223.4 \mathrm{Gg}$ as of 2004. TURKSTAT estimates that aggregate $\mathrm{CO}_{2}$ emissions from energy production will reach to $343 \mathrm{Gg}$ by 2010 and to $615 \mathrm{Gg}$ by 2020 . According to data the significant share of $\mathrm{CO}_{2}$ emissions originate from electricity production. On a per capita basis, consumption of electricity in Turkey has increased by 6-folds from 1980 to 2005, and is expected to increase to $400 \mathrm{kWh}$ per person by 2010 .

With increased production capacity and increased consumption demand, Turkish energy intensities are projected to rise. This fact is openly exposed in the country's growing reliance on electricity generation. Gross electricity generation is observed to almost double from $86,247 \mathrm{GWh}$ in 1995 to $149,982 \mathrm{GWh}$ in 2004 . This rapid expansion gives an annual average rate of growth of $7.2 \%$ over the mentioned period. ${ }^{5}$

The sectoral breakdown of energy consumption and primary resource production indicates the growing national imbalances as the domestically supplied share of total energy demand has continuously fallen from $48.1 \%$ in 1990 to $27.8 \%$ in 2004 . All these reveal a sustained domestic deficit, given the expectations of a very significant rise in final energy demand in the next decade. The Ministry of Energy and Natural Resources (MENR) estimates indicate that total energy demand in Turkey will reach 135,302 thousand tonnes of oil equivalent (TOE) and per capita energy will rise from $1276 \mathrm{kgoe}$ in 2005 , to $1663 \mathrm{kgoe}$ in 2013 . These broad shifts underscore that

\footnotetext{
${ }^{5}$ Data suggest network losses of $17 \%$ on the average annually. This leaves the country with net consumption of 111,766 GWh in 2003 and 118,050 GWh in 2004.
} 
Turkey has not yet stabilized its energy demand, and pressures of a newly industrialized economy continues to be felt. ${ }^{6}$

Given the limited substitution possibilities for energy use and the unstable/dynamic character of the production activities, it becomes hard to offer viable guidelines on the available menu of abatement policies.

\section{The algebraic structure of the model}

Given the above overview of the economic and political realm, we now develop our analytical CGE model for Turkey to study issues of environmental abatement and its economic impacts. Although there is a variety of CGE modeling exercises for Turkey, environmental modeling applications are relatively new and scarce. Roe and Yeldan (1996), Boratav, Türel, \& Yeldan (1996), Şahin (2004) and Kumbaroğlu (2003), Tunç, Türüt-Aşık, \& Akbostancı (2006) are among the few contributions in this respect. ${ }^{7}$

The model that we present here should be considered as a first step to establish a "base-path" over 2006-2020 against which the socio-economic impacts of alternative policy scenarios are investigated. "Dynamics" are integrated via "exogenous" updating of the static model into a medium-run of 15 years using estimates on average population growth, investment behavior on the part of both private and public sectors, and total factor productivity (TFP) growth.

The supply-side of the economy is modeled as 10 aggregate sectors. In line with our focus on environmental policy evaluation, the disaggregation scheme of the overall economy develops into the energy sectors and critical sectors of GHG pollutions in detail. It thus, aggregates a large number of other activities that, although being far more important contributors to total gross output, are not germane to the climate problem. The sectors that we specify are: Agricultural Production (AG); Coal Mining (CO); Petroleum and Gas (PG); Refined Petroleum (RP); Electricity Production (EL); Cement Production (CE); Paper Production (PA); Iron and Steel Production (IS); Transportation (TR); and a composite of remaining manufacturing, services and primary industries sectors of the economy (OE). Labor, capital and a composite of primary energy inputs, electricity, petroleum and gas and coal, together with intermediate inputs comprise the sectorial factors of production.

\subsection{Production structure, factor endowments}

Fig. 2 represents the general production structure of the model. In what follows, we provide a bird's-eye overview of the model, and invite the interested reader to contact us directly for further documentation of its full algebraic structure. Sectoral production is modeled via two-stage production technology where at the second stage, gross output is produced through a Cobb-Douglas

\footnotetext{
6 The MENR also estimates investment needs for meeting the increased pace of industrialization and needs of new consumption. Accordingly, Turkey will need to invest a total of US\$233.4 billion over 2005-2020. US\$ 5.1 billion of this sum is expected to be spent over coal exploration and production and US\$ 104.8 billion (about 43\%) is expected to be spent on electricity generation.

7 Apart from CGE applications, there is also a relatively small number of studies that try to fill in the gap of multidimensional need for studying energy-environment-economy issues for Turkey. Karakaya and Özçă̆ (2001) analyze a set of economic instruments that may be relevant to use for sustainable development under climate change. Ediger and Huvaz (2006), with the aid of a decomposition analysis provide estimates of sectoral energy usage in Turkish economy. Lise (2006) decomposes factors that explain $\mathrm{CO}_{2}$ emissions between 1980 and 2003 for Turkey.
} 


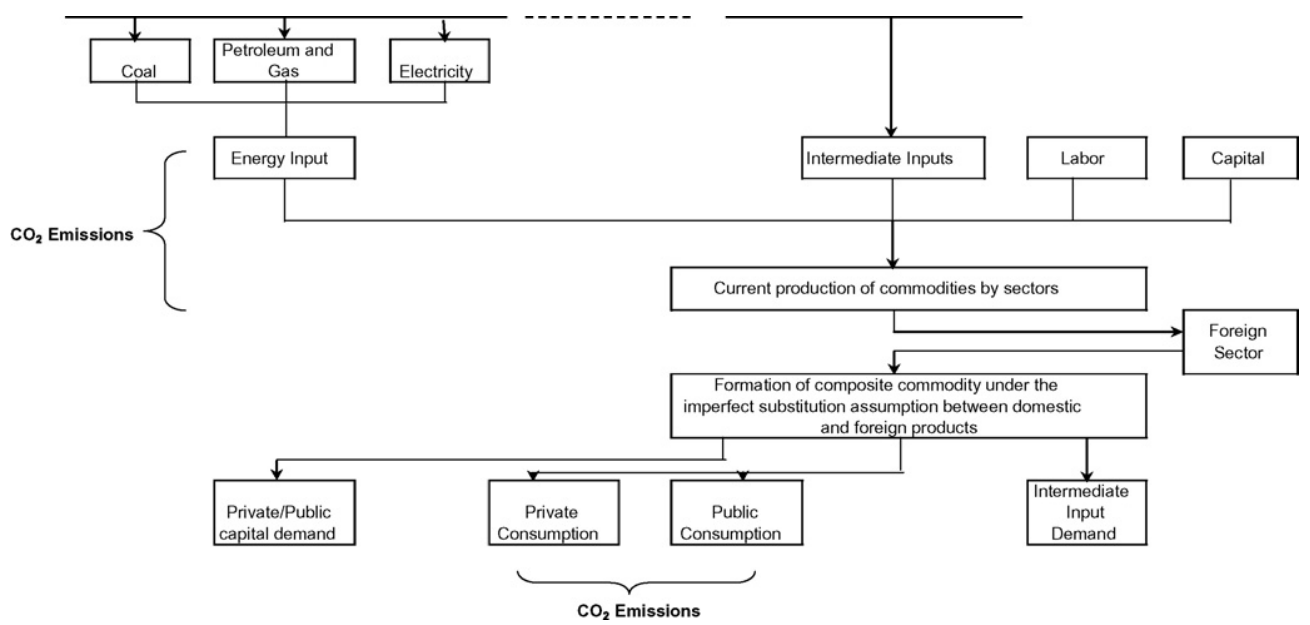

Fig. 2. Flows of commodities, factors and emissions in the model.

technology defining capital $(K)$, labor $(L)$, intermediate inputs-excluding primary energy inputs (ID) and primary energy composite (ENG) as factors of production:

$$
X S_{i}=A X_{i}\left[K_{i}^{\lambda_{\mathrm{K}, i}} L_{i}^{\lambda_{\mathrm{L}, i}}\left(\prod_{j} \mathrm{ID}^{\lambda_{\mathrm{ID}, j, i}}\right) \mathrm{ENG}_{i}^{\lambda_{\mathrm{E}, i}}\right]
$$

where $i$ : AG, CO, PG, RP, EL, CE, PA, IS, TR, OE.

In Eq. (1), $A X$ is the technology level parameter, $\lambda_{\mathrm{K}, i}, \lambda_{\mathrm{L}, i}, \lambda_{\mathrm{E}, i}$ denote the shares of capital input, the labor input and the energy input in the value of gross output in sector $i$.

At the initial stage of the production technology in each sector, the primary energy composite is produced along a constant elasticity of substitution (CES) production function using the primary energy inputs, coal, petroleum and gas and electricity:

$$
\mathrm{ENG}_{i}=\mathrm{AE}_{i}\left[\kappa_{\mathrm{CO}, i} \mathrm{ID}_{\mathrm{CO}, i}^{-\rho x_{i}}+\kappa_{\mathrm{PG}, i} \mathrm{ID}_{\mathrm{PG}, i}^{-\rho x_{i}}+\kappa_{\mathrm{EL}, i} \mathrm{ID}_{\mathrm{EL}, i}^{-\rho x_{i}}\right]^{-1 / \rho x_{i}}
$$

Under the above production technology, differentiation of the minimum cost per unit of primary energy inputs gives the sectoral demand for coal, petroleum and gas and electricity:

$$
\frac{\mathrm{ID}_{j, i}}{\mathrm{ENG}_{i}}=\left[\frac{\kappa_{j, i} P_{i}^{\mathrm{ENG}}}{\mathrm{AE}_{i}^{-p x_{i}}\left(1+\mathrm{CO}_{2} t N_{j}\right) P_{i}^{\mathrm{C}}}\right]^{1 /\left(1+\rho x_{i}\right)}
$$

where $j$ : CO, PG, EL.

Sectoral demands for labor, capital, energy composite and intermediate inputs arise from the profit-maximization behavior of the representative firm in each sector.

To capture the extent of informalization in the labor markets, a wide ranging phenomenon of the Turkish manufacturing industry (see e.g., Agénor, Jensen, Verghis, \& Yeldan, 2007; Ercan \& Tansel, 2006; Telli, Voyvoda, \& Yeldan, in press; Tunal1, 2003), we introduce open unemployment via a fixed nominal wage. Physical capital, in turn, is regarded mobile, and it is the difference in sectoral profit rates that leads to the sectoral allocation of aggregate investments in within-period dynamics of the model. 


\subsection{Environmental emissions and taxation}

Three basic sources of $\mathrm{CO}_{2}$ emissions are distinguished in the model: (i) due to (primary and secondary) energy usage, (ii) due to industrial processes, and (iii) due to energy use of households. Total $\mathrm{CO}_{2}$ emission in the economy is the sum over from all these sources. The emissions from industrial processes is regarded to depend on the level of industrial activity, and is regarded proportional to gross output:

$$
\mathrm{CO}_{2} \mathrm{EM}_{i}^{\mathrm{IND}}=\bar{\delta}_{i} X S_{i}
$$

On the other hand, total emissions due to energy usage originate from two sources: sectoral emissions due to combustion of primary energy fuels (coal and petroleum and gas), and sectoral emissions due to combustion of secondary energy fuels (refined petroleum):

$$
\mathrm{TOTCO}_{2} \mathrm{ENG}=\sum_{i}\left[\sum_{j}\left(\mathrm{CO}_{2} \mathrm{EM}_{j, i}^{\mathrm{INM}}+\mathrm{CO}_{2} \mathrm{EM}_{j, i}^{\mathrm{ENG}}\right)\right]
$$

Under both sources, the mechanism of emission is dependent on the level of pollutant-emitting inputs (energy input at primary and at secondary levels) in each sector:

$$
\begin{aligned}
\mathrm{CO}_{2} \mathrm{EM}_{j, i}^{\mathrm{ENG}}=\varpi_{j, i} \mathrm{ID}_{i j}, & j=\mathrm{CO}, \mathrm{PG} \\
\mathrm{CO}_{2} \mathrm{EM}_{j, i}^{\mathrm{INM}}=\bar{\varepsilon}_{j, i} \mathrm{ID}_{j, i}, & j=\mathrm{RP}
\end{aligned}
$$

Finally, total emission of $\mathrm{CO}_{2}$ in the use of energy by households is given by:

$$
\mathrm{TOTCO}_{2} \mathrm{HH}=\sum_{i} \bar{\psi}_{i} \mathrm{CD}_{i}
$$

where $\bar{\psi}_{i}$ is the coefficient of emissions of $\mathrm{CO}_{2}$ in private consumption $\left(\mathrm{CD}_{i}\right)$ of the basic fuels coal (CO) and refined petroleum (RP) by households.

Carbon tax is introduced via at rates $\mathrm{CO}_{2} \mathrm{tP}, \mathrm{CO}_{2} \mathrm{tN}_{i}$ and $\mathrm{CO}_{2} \mathrm{tC}_{i}$ per tonnes of carbon dioxide emitted, on production, on intermediate input usage, and on consumption, respectively. The revenues are directly added to the revenue pool of the government budget.

\subsection{Income generation and demand}

Returns to labor input, net of social security taxes, constitute the private household net labor income. Net profit transfer of the enterprise income to private household is mainly composed of returns to capital as a factor of production. Thus, the primary sources of income, together with the secondary sources of income from public and foreign transfers constitute the total private income to the households. Private households save a constant fraction, $s^{p}$ of their income. The residual aggregate private consumption is distributed into sectoral components through exogenous (and calibrated) shares.

Aggregate public consumption is specified to be a constant fraction of aggregate public income. The government carries on income transfers to the households, to the enterprises and to the social security system in fixed proportions of government revenues net of interest payments. Furthermore, the government is constrained by an exogenously set target of a primary surplus/GNP 
ratio. ${ }^{8}$ Fiscal closure is imposed by setting public investment demand as a residual variable to adjust endogenously, given the available net fiscal revenues.

The resultant public sector borrowing requirement, PSBR is either financed by domestic borrowing, $\Delta$ DomDebt $^{\mathrm{G}}$ or by foreign borrowing $\Delta \varepsilon$ ForDebt $^{\mathrm{G}}$.

\subsection{General equilibrium and dynamics}

The overall model is brought into equilibrium through endogenous adjustments of product prices to clear the commodity markets and balance of payments accounts. With nominal wages fixed in each period, equilibrium in the labor market is sustained through adjustments of employment.The aggregate saving-investment balance (Walras' Law) is maintained by the following:

$$
\text { PrivSAV }+ \text { GovSAV }+\varepsilon \text { CAdef }=\text { PrivINV }+ \text { GovINV }
$$

The CAdef in the equation above determines the current account balance in foreign prices and equals to the export revenues, the remittances and private and public foreign borrowing on the revenue side, and the import bill, profit transfers abroad and interest payments on the accumulated private and public debt stocks on the expenditures side.

The private and public components of the external capital inflows are fixed in their foreign exchange terms. The additional endogenous variable of the system to close is the private investments, PrivINV.

The model updates the annual values of the exogenously specified variables and the policy variables in an attempt to characterize the 2006-2020 growth trajectory of the economy. Inbetween periods, first we update the capital stocks with new investment expenditures net of depreciation. Labor endowment is increased by the population growth rate. Similarly, technical factor productivity rates are specified in a Hicks-neutral manner.

We also account for the evolution of debt stocks. Given aggregate PSBR, government's foreign borrowing is taken as a constant ratio:

$$
\varepsilon \text { ForBor }^{\mathrm{G}}=(\text { gfborrat}) \text { PSBR }
$$

while the rest is met by domestic borrowing.

Finally, the exchange rate, $\varepsilon$, is set as the 'numéraire' of the system.

\section{Calibration and the base-path for 2003-2020}

All policy scenarios are portrayed with respect to a base-run reference scenario. Having calibrated the parameter values, we construct a benchmark economy for the 2003-2020 period, under the following:

- No specific environmental policy action/taxation/quota (business-as-usual environmental policy).

- $2 \%$ annual total factor productivity growth rate on average (differentiated for agriculture and industry sectors).

\footnotetext{
8 The current target for the ratio of the primary surplus (excess of public sector revenues over non-interest public expenditures) to the GNP is $6.5 \%$ under the ongoing stand-by with the IMF (2003-2008).
} 


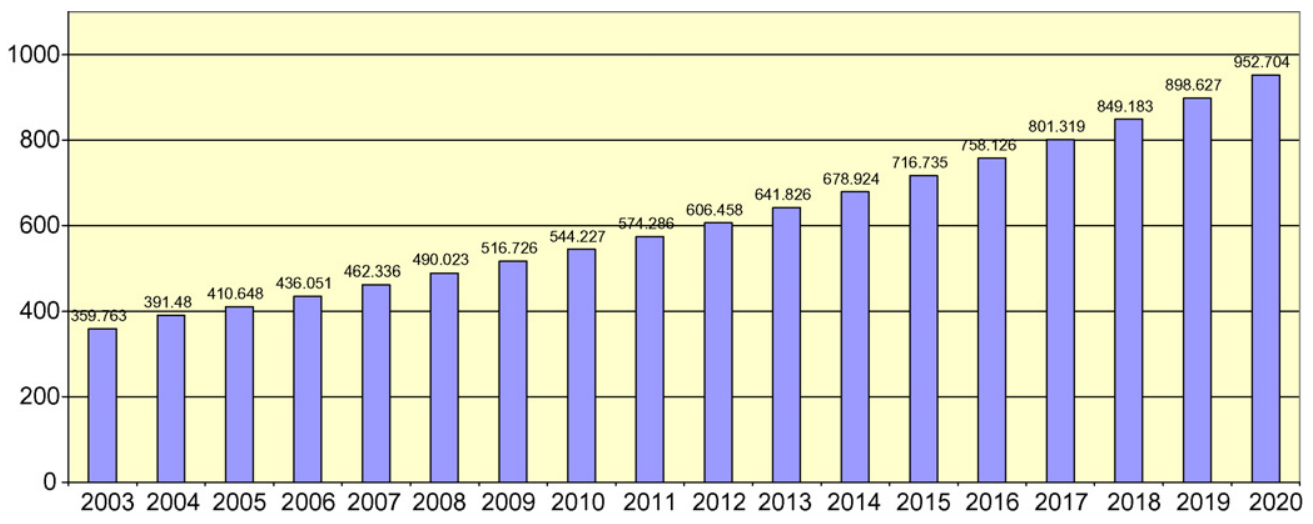

Fig. 3. Base-run real GDP (billion TRY, fixed 2003 prices). Source: Authors' computations.

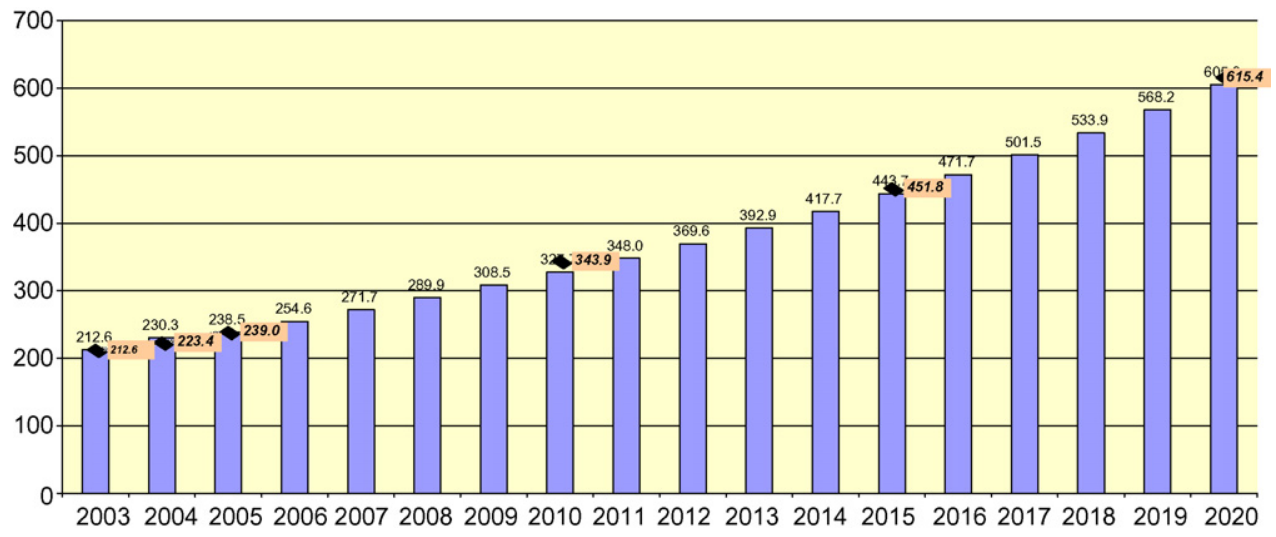

Fig. 4. Base-run total $\mathrm{CO}_{2}$ emissions from energy (million tonnes). Source: Authors' computations.

- Exogenously determined foreign capital inflows.

- Endogenous (flexible) real exchange rate under the constraint of the current account balance.

- Exogenously fixed real wage rate.

- Fiscal policy in accordance with the announced policy rule of targeted primary surplus.

Fig. 3 portrays the likely path of the real GDP under the base-run, the reference model. As observed, the annual real GDP growth rate stays around 6\% throughout the 2003-2020 period and the real GDP reaches to a value of 952.7 billion TRY by 2020. Fig. 4, on the other hand, illustrates the $\mathrm{CO}_{2}$ emissions from energy (fuel combustion) as compared to point estimates of the same variable by TURKSTAT. As the figure clearly indicates, the values are comparable to that of TURKSTAT, reported to reach 615.4 million tonnes of $\mathrm{CO}_{2}$ by $2020 .{ }^{9}$ As the decomposition analysis of Lise (2006) shows, as in any other relatively fast growing economy, the biggest contributor to the rise in $\mathrm{CO}_{2}$ emissions in Turkey is the expansion of the economy (scale effect). The recent projections of the OECD show that Turkey has an annual growth potential of above

\footnotetext{
${ }^{9}$ The growth path is projected to generate an aggregate $\mathrm{CO}_{2}$ emission level of 656.4 million tonnes in 2020.
} 
$7 \%$ (OECD, 2004). UNDP and the World Bank (2003) provide a projection of a 6-fold increase in greenhouse gas emissions by 2025 with respect to 1990 level. The study foresees an annual increase of $5.9 \%$ in final energy consumption. Given different projections of the growth paths to an extent, we thus observe that the base-run values are well within the ranges reported by TURKSTAT and the international agencies.

Under this growth path of the base-run, given that the production technology parameters are constant, the $\mathrm{CO}_{2}$ emissions per real GDP also show an increasing trend, by showing almost $10 \%$ increase in 2020, compared to 2003 value.

\section{CGE analysis of alternative environmental policy scenarios}

Now we turn to implementing alternative environmental policy scenarios using our modeling framework. In what follows, we will group our policy interventions into two broad categories: first, we will implement tax and quota based instruments with no additional abatement investments. That is the production-emission structure of the economy remains as it is. The environmental tax revenues (or subsidy costs) is administered through the central fiscal budget with no further design on investments to change the energy use and production structure of the economy. Under the second categorization, a more active environmental policy stance is taken and the implemented policy instruments are complemented with an active abatement investment policy. The abatement investment is funded either from environmental tax revenues or from other sources, such as foreign credit and/or national savings.

First we ask the straight question: "what will the economic impacts of maintaining lower $\mathrm{CO}_{2}$ emissions in the aggregate for the Turkish economy?"

\subsection{Implement carbon emission quotas directly}

What if one imposes a straightforward, direct quota on the Turkish industries complemented by pollutant fees? What happens to the economic variables of direct quotas on aggregate $\mathrm{CO}_{2}$ emissions over the 2005-2020 time horizon? Assuming that such quotas are enforced with the accompaniment of pollutant fees, what is the tax burden? How will this burden affect the producers and investors in their production plans? And consumers? Finally, what will be the net effect of this policy framework on government's fiscal balances, on trade balance, and on unemployment?

These are the questions that we would like to tackle in this first set of scenarios. To this end, we impose a straight aggregate quota of three alternative levels on the 2005-2020 growth path of the Turkish economy: (i) $90 \%$ quota (i.e., reducing emission by $10 \%$ of the base-run); (ii) $80 \%$ quota; and (iii) $60 \%$ quota. To enforce the quotas, a pollutant fee system is activated. The fees are to be paid according to the polluter pays principle and are to be collected by the fiscal authority directly. No other possible use of such funds for further environmental policy such as abatement investments or any subsidization is envisaged. Thus, in a nutshell this scenario gives the very basic, command and control approach in achieving $\mathrm{CO}_{2}$ emission targets. The simplicity of this scenario is desirable as its results will offer us the most direct and basic outcomes of a very clear policy instrument to achieve the $\mathrm{CO}_{2}$ goals in the most straightforward manner. We then build over this simple framework and reach more complex policy packages, yet at each level the outcomes derived from this basic framework will be used as a benchmark.

Table 2 portrays a set of key variables under different quota and tax policies. If a quota of $90 \%$ is imposed, the rate of growth of GDP is reduced and total GDP falls by $7.1 \%$ in comparison 
Table 2

The incidence of $\mathrm{CO}_{2}$ emission quotas and taxes on energy input

\begin{tabular}{|c|c|c|c|c|c|c|}
\hline & Base-run & $\begin{array}{l}\text { Under } 90 \% \\
\text { quota }\end{array}$ & $\begin{array}{l}\text { Under } 80 \% \\
\text { quota }\end{array}$ & $\begin{array}{l}\text { Under } 60 \% \\
\text { quota }\end{array}$ & $\begin{array}{l}\text { Under } 10 \% \text { tax } \\
\text { on energy }\end{array}$ & $\begin{array}{l}\text { Under } 20 \% \text { tax } \\
\text { on energy }\end{array}$ \\
\hline \multicolumn{7}{|c|}{ GDP (2003 prices, billions TRY) } \\
\hline 2006 & 436.051 & 412.656 & 387.652 & 328.629 & 431.689 & 427.372 \\
\hline 2008 & 490.023 & 461.451 & 430.940 & 359.300 & 483.061 & 476.332 \\
\hline 2012 & 606.458 & 565.996 & 522.894 & 422.468 & 591.978 & 578.398 \\
\hline 2020 & 952.704 & 876.495 & 795.750 & 608.880 & 908.290 & 868.182 \\
\hline \multicolumn{7}{|c|}{ Private investment (2003 prices, billions TRY) } \\
\hline 2006 & 127.822 & 119.389 & 110.556 & 91.443 & 126.578 & 125.368 \\
\hline 2008 & 141.668 & 131.680 & 121.197 & 98.470 & 139.669 & 137.762 \\
\hline 2012 & 173.476 & 159.829 & 145.450 & 114.121 & 169.229 & 165.276 \\
\hline 2020 & 279.287 & 253.973 & 227.087 & 167.785 & 265.604 & 265.604 \\
\hline \multicolumn{7}{|c|}{ Total $\mathrm{CO}_{2}$ emissions (million tonnes) } \\
\hline 2006 & 276.953 & 249.258 & 221.562 & 166.172 & 243.775 & 217.507 \\
\hline 2008 & 315.187 & 283.668 & 252.150 & 189.112 & 276.557 & 246.014 \\
\hline 2012 & 401.368 & 361.231 & 321.094 & 240.821 & 349.440 & 308.568 \\
\hline 2020 & 656.399 & 590.759 & 525.119 & 393.839 & 559.679 & 484.719 \\
\hline \multicolumn{7}{|c|}{ Total $\mathrm{CO}_{2}$ emissions as a ratio to GDP (million tonnes/billion TRY) } \\
\hline 2006 & 0.635 & 0.604 & 0.572 & 0.506 & 0.565 & 0.509 \\
\hline 2008 & 0.643 & 0.615 & 0.585 & 0.526 & 0.573 & 0.516 \\
\hline 2012 & 0.662 & 0.638 & 0.614 & 0.570 & 0.590 & 0.533 \\
\hline 2020 & 0.689 & 0.674 & 0.6160 & 0.647 & 0.616 & 0.558 \\
\hline \multicolumn{7}{|c|}{$\mathrm{CO}_{2}$ tax revenues as a ratio to $\mathrm{GDP}(\%)$} \\
\hline 2006 & & 4.131 & 8.597 & 18.349 & 0.470 & 0.849 \\
\hline 2008 & & 3.815 & 7.941 & 16.928 & 0.471 & 0.852 \\
\hline 2012 & & 3.203 & 6.660 & 14.061 & 0.474 & 0.856 \\
\hline 2020 & & 2.057 & 4.218 & 8.169 & 0.478 & 0.863 \\
\hline
\end{tabular}

Source: Authors' computations.

to the base-run 2020 value. In contrast, if the quota is set at $60 \%$ of aggregate emissions of the base-path, the GDP of 2020 is observed to fall to 602 billion TRY. This implies a reduction of $36.8 \%$.

Our results indicate that the $\mathrm{CO}_{2}$ quotas affect the economy in a non-linear fashion. Higher rates of $\mathrm{CO}_{2}$ restrictions have an increasingly higher burden with subsequent production losses. The overall elasticity of emission gains to GDP losses is -1.1 , that is a $40 \%$ reduction in $\mathrm{CO}_{2}$ emissions through an outright quota is associated with a $36.8 \%$ loss of GDP. In this case, summing over the whole analyzed period, 2006 - 2020, the cumulative loss of GDP amounts to 1145 billions 2003 TRY.

The scenario is accompanied with a $\mathrm{CO}_{2}$ tax to enforce the emission quotas. We find that total incidence of the $\mathrm{CO}_{2}$ tax revenues as a ratio to the GDP is marginal for the $90 \%$ quota target. Yet, for enforcing a quota of $80 \%$, the necessary tax burden is almost $10 \%$ upon implementation, and remains above $5 \%$ for the remaining of the projected time horizon. If a quota of $60 \%$ is imposed the tax burden is $20 \%$ to the GDP and falls only to $12 \%$ in 2020 . Thus, the model results suggest that for a return of $40 \%$ reduction in aggregate emissions in 2020 , a $\mathrm{CO}_{2}$ tax of $12 \%$ to the GDP is to be implemented. No wonder, this is an important interference to the economy and our results reveal that attempts to restrict the path of $\mathrm{CO}_{2}$ emissions using fiscal measures 
alone will necessitate a very high tax incidence and significant deadweight loss? In other words, the sensitivity of the production units to fiscal tax measure is very low, and that restricting $\mathrm{CO}_{2}$ emissions in a growing economy is very costly and is very difficult to enforce.

The increased tax burden generates strong crowding-out effects and calls for reductions in private investments. Private investment expenditures are cut by $4 \%$ under the $90 \%$ quota but the rate of reduction is very non-linear as above (see Table 2). Under the $60 \% \mathrm{CO}_{2}$ quota, the private investment expenditures are reduced almost by half.

The fall in private expenditures is the major reason of the fall in aggregate GDP and the consequent rise of unemployment. These macroeconomic outcomes of course are very crude approximations of reality. Needless to mention, the outright transfer of $\mathrm{CO}_{2}$ tax monies to the central budget with no further environmental policy in action clearly is inferior to one that can be complemented with further alternatives. Before turning towards these issues, however, it would be informative to study the microeconomic (sectoral) substitution possibilities of the environmental policy at hand, and for this purpose we turn our attention next to an energy tax, rather than a direct carbon tax.

\subsection{Economic effects of taxing energy input use in production}

Our framework admits three sources of energy inputs: coal, petroleum and gas, and electricity. Given the substitution possibilities between energy sources and factor use (capital and labor), the cost minimization procedures will signal the producers to save on energy utilization and thereby reduce $\mathrm{CO}_{2}$ emitted. We implement the energy taxation policy at two levels: 10 and $20 \%$ tax.

The energy taxation at $10 \%$ leads to a reduction of total $\mathrm{CO}_{2}$ emissions by $14.2 \%$ by 2020 . If the tax rate is set at $20 \%$, the abatement rate reaches to $25.3 \%$ (see Table 2). The energy taxation seems to have higher policy effectiveness in combating $\mathrm{CO}_{2}$ pollution at the aggregate level in contrast to taxing overall emissions. Since the major source of $\mathrm{CO}_{2}$ pollutants originate from energy use, a taxation policy destined to economize on energy intensities seem to produce more efficient results to this end.

The overall tax burden of the current policy further illustrates this point. The model results suggest that the fiscal tax revenues from a $10 \%$ energy tax reach to only $0.48 \%$ of the GDP, and that from the imposition of $20 \%$ tax is $0.85 \%$ of the GDP. Thus, in contrast to the significant burden of overall carbon taxes experienced in the previous scenarios, the energy taxation seem to carry lesser distortion to the domestic economy.

The loss in GDP from the imposition of a $20 \%$ energy tax rate is $7.4 \%$ in 2020 in comparison to the base-run (business-as-usual). Thus, to summarize, the model results suggest that the $20 \%$ energy taxation reduces overall $\mathrm{CO}_{2}$ emissions by $25.3 \%$, and is accompanied by a loss of aggregate GDP by $8.8 \%$ over the base-run by 2020 . In contrast, the same figures were $14.2 \% \mathrm{CO}_{2}$ abatement rate in return to $10 \%$ energy tax and a loss of 3.9\% in GDP level in 2020.

These results contrast with the very adverse effects of the current policy on the employment levels. The results indicate significant unemployment rates under the taxation regimes. The rate of open unemployment is observed to reach $15 \%$ under the $10 \%$ tax rate, and reaches $19 \%$ for the imposition of the $20 \%$ tax rate on energy use. In contrast, the base-run path reveals a rate of unemployment of around $10 \%$ for most of the modeled time horizon (Fig. 5).

The rise of the unemployment rate under this scenario is due to the imposed distortions on cost minimization by introducing input taxes. To the extent that labor is complementary to energy use, the consequent rise in the costs of energy use leads to a fall in the demand for labor as well. With limited factor substitution possibilities in the medium run, producers meet the increased energy costs by cutting demand not only for energy use, but also for labor employment, as well. 


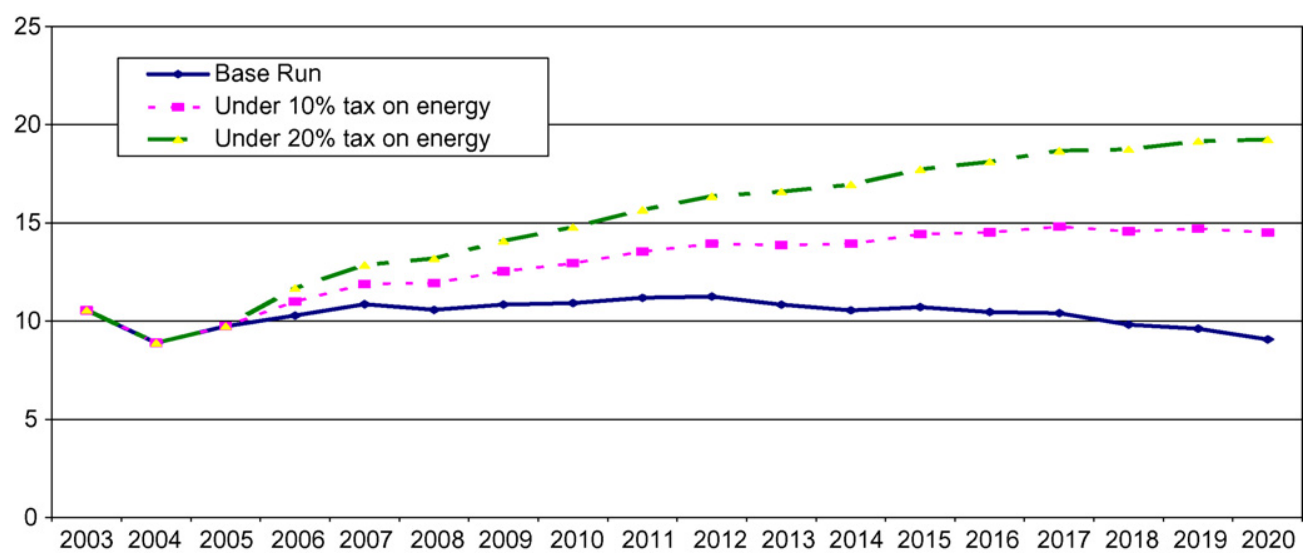

Fig. 5. Unemployment rate under alternative energy tax scenarios. Source: Authors' computations.

These results suggest that a proper mix of environmental taxation should be accompanied with reductions in labor taxes and/or increased employment subsidies. Such a policy mix seems to be a superior policy in achieving both $\mathrm{CO}_{2}$ abatement targets and maintaining employment rates across sectors. Furthermore, one observes a clear need for supplementing the market-based incentives along with direct abatement investments to reduce energy intensities and improve upon the existing pollution technologies.

\subsection{Environmental policy instruments with abatement investments}

An important issue in developing policies for the mitigation of GHG emissions is to determine a "feasible" set of policies to generate emission reductions and to make investments in energy-saving technologies. Estimating both the costs and effectiveness of these policies in emission-reduction is a very important, yet a challenging issue. For instance, a recent study on the "Economic Evaluation of Sectoral Emission Reduction Objectives for Climate Change" conducted for EU countries project a marginal cost as low as 20-25 per tonnes $\mathrm{CO}_{2}$ eq. in $1999 €$ for the EU countries. ${ }^{10}$ The marginal cost is estimated to be $1999 € 3.7$ billion annually during the first budget period of the protocol (2008-2012), which is equivalent to about $0.06 \%$ of EU gross domestic product in 2010.

For the Turkish economy a similar study has yet to address the issues of estimating the costs of feasible policies to make investments in especially energy-saving, emission-reducing and costeffective technological change that would be attractive to producers. In the absence of precise technological cost-benefit estimates of such investments, we compare alternatives of burden-sharing between different groups in the economy, under a reference abatement-investment scenario.

\subsection{Abatement investments affecting capital accumulation}

Specifically, in the reference abatement-investment scenario, we follow the State Planning Organization (SPO) estimates and implement energy-saving $\left(\mathrm{CO}_{2}\right.$ emission-reducing) abatementinvestments of $1.5 \%$ of the GDP in 2006-2020. The SPO's estimate is that such investments

\footnotetext{
10 The projection is developed by the National Technical University of Athens, Ecofys and AEA Technology and analyzed with the GENESIS database. It is based on EU-wide allocation of least-cost objective for different sectors.
} 
Table 3

The incidence of abatement investments

\begin{tabular}{|c|c|c|c|c|}
\hline & Base-run & $\begin{array}{l}\text { Under abatement investment } \\
\text { affecting capital account }\end{array}$ & $\begin{array}{l}\text { Under abatement investment } \\
\text { financed by energy taxes }\end{array}$ & $\begin{array}{l}\text { Under abatement investmnet } \\
\text { financed by foreign aid }\end{array}$ \\
\hline \multicolumn{5}{|c|}{ GDP (2003 prices, billions TRY) } \\
\hline 2006 & 436.051 & 429.929 & 418.168 & 436.051 \\
\hline 2008 & 490.023 & 478.235 & 461.035 & 490.023 \\
\hline 2012 & 606.458 & 579.218 & 544.509 & 606.458 \\
\hline 2020 & 952.704 & 868.749 & 755.019 & 952.704 \\
\hline \multicolumn{5}{|c|}{ Private investment (2003 prices, billions TRY) } \\
\hline 2006 & 127.822 & 126.166 & 122.037 & 127.822 \\
\hline 2008 & 141.668 & 138.436 & 131.672 & 141.668 \\
\hline 2012 & 173.476 & 165.776 & 131.672 & 173.476 \\
\hline 2020 & 279.287 & 254.034 & 204.211 & 279.287 \\
\hline \multicolumn{5}{|c|}{ Total $\mathrm{CO}_{2}$ emissions (million tonnes) } \\
\hline 2006 & 276.953 & 272.201 & 238.617 & 276.038 \\
\hline 2008 & 315.187 & 304.734 & 266.294 & 312.063 \\
\hline 2012 & 401.368 & 375.168 & 322.941 & 392.084 \\
\hline 2020 & 656.399 & 571.459 & 460.917 & 624.091 \\
\hline \multicolumn{5}{|c|}{ Total $\mathrm{CO}_{2}$ emissions as a ratio to GDP (million tonnes/billion TRY) } \\
\hline 2006 & 0.635 & 0.633 & 0.571 & 0.633 \\
\hline 2008 & 0.643 & 0.637 & 0.578 & 0.637 \\
\hline 2012 & 0.662 & 0.648 & 0.593 & 0.647 \\
\hline 2020 & 0.689 & 0.658 & 0.610 & 0.655 \\
\hline
\end{tabular}

Source: Authors' computations.

will help reducing the energy-input related emission coefficients by $5 \%$. We will adhere to this assumption in modeling of the abatement investment scenarios.

The question is "what will happen, if total abatement investments (estimated at $1.5 \%$ of GDP annually in 2006-2020) are undertaken by both the private and public production units to achieve a 5\% reduction in emission coefficients of the primary-energy inputs?" As the cost is undertaken totally by the investing sectors of the economy, it is clear that abatement investments will necessarily absorb a portion of funds away from physical capital accumulation. Thus, compared to base-run, the aggregate capital stock is expected to be reduced by the extent of such abatement investments.

Table 3 illustrates the simulated paths of the real GDP, private investment and $\mathrm{CO}_{2}$ emissions under the base-run and three alternatives: under abatement investments affecting capital accumulation, under abatement investments financed by energy-input taxation, and under abatement investments financed by foreign aid.

The deceleration of the rate of physical capital investments becomes the major reason in the slow down of the GDP growth. ${ }^{11}$ The real GDP under the scenario is found to be $5 \%$ lower than the corresponding value under base-run. Thus, the GDP growth rate is lower as well. This lower growth performance emerges as a result of the fall in the pace of capital accumulation, since a portion of investment now has been allocated for energy-saving, emissions-reducing technological change.

\footnotetext{
11 Because we have kept a positive growth rate for the change in total factor productivity growth at a rate of $2 \%$ we have assumed no additional ( $a d$ hoc) effects of the abatement investments on further improvements in the rate of growth of technology.
} 
As investments lead to more efficient use of energy inputs and the emission coefficients on primary energy usage are effectively reduced, total $\mathrm{CO}_{2}$ emissions are reduced. Such an application brings a total reduction of 549.3 million tonnes of $\mathrm{CO}_{2}$ throughout 2003-2020 period. This value amounts to almost $7.5 \%$ of total emission level of the base-run. The annual reduction values indicate an average of $7.2 \%$ throughout the period, but as the reduction technology settles in, gains from emissions become more visible reaching as high as $15 \%$ of the baseline in 2020.

\subsection{Abatement investments under tax-financing versus foreign aid policies}

Having observed the (potential) trade-off effects in allocation of funds towards abatement investments and away from capital investments (causing reduction in GDP), we next search for alternatives to finance the abatement investments. One alternative is that the government carries out the necessary investment expenditures (amounting to 1.5\% of GDP, annually between 2006 and 2020), yet imposes additional taxes on the usage of polluting energy inputs (primary and secondary) in the production sectors to finance the investment projects. We find that the intermediate energy usage tax policy results in a tax rate of $23 \%$ on the usage of refined petroleum $(\mathrm{RP})$, petroleum and gas (PG) and coal (CO) in the production sectors.

The other alternative that we explore in this study is inspired by one "flexible" mechanism of the Kyoto protocol: the joint implementation (JI) mechanism that may be used by Annex-I parties to fulfill their own Kyoto targets. ${ }^{12}$ We assume the JI mechanism would offer incentives for the developed countries (Annex-II) to be actively involved in projects; towards emission reductions. So, in this scenario, we assume the abatement investments are financed by some form of foreign aid.

When abatement investments are financed by taxation of energy inputs, the pace of economic activity slows down, compared to both the baseline scenario and the scenario under foreign aid. The scenario under foreign aid generates much favorable growth rates compared to the other two cases, nevertheless since the economic activity is high, the total $\mathrm{CO}_{2}$ emissions also rises. Yet, the abatement investments (which we assume effective in emission reduction) still accomplish a $3 \%$ reduction of total $\mathrm{CO}_{2}$ emissions, compared to base-run.

Before making commitments on possible policy alternatives, we find it informative to study the microeconomic sectoral) results of the scenarios we analyze. In Table 4, we display the outputs of the production sectors represented in our model economy.

In comparison to the base-run, the sectoral output productions and sectoral emission reductions are quite parallel under the first scenario of abatement investments financed by funds away from capital accumulation, since the production sectors are bound to take this measure towards $\mathrm{CO}_{2}$ emission reductions in an indiscriminate manner. Therefore, the overall economy is affected proportionally. On the other hand, financing of abatement investments by energy-input taxation works quite selectively: the sectors that experience the highest reduction (in comparison to baserun), in their output levels are the most energy-intensive sectors. Over 2006-2020, the output

12 The basic principles of the JI mechanism are defined in Article 6 of the protocol:

"For the purpose of meeting its commitments ... any party included in Annex-I may transfer to, or acquire from, any other such party emission reduction units resulting from projects aimed at reducing anthropogenic emissions by sources or enhancing anthropogenic removals by sinks of GHGs in any sector of the economy provided that certain (participation) requirements are fulfilled." 
Table 4

Sectoral outputs under alternative scenarios (in 2003 prices, billions TRY)

\begin{tabular}{|c|c|c|c|c|c|c|c|c|c|}
\hline & \multicolumn{3}{|c|}{ Base-run } & \multicolumn{3}{|c|}{$\begin{array}{l}\text { Under abatement investment } \\
\text { affecting capital account }\end{array}$} & \multicolumn{3}{|c|}{$\begin{array}{l}\text { Under abatement investment } \\
\text { financed by energy taxes }\end{array}$} \\
\hline & 2006 & 2012 & 2020 & 2006 & 2012 & 2020 & 2006 & 2012 & 2020 \\
\hline AG: Agriculture & 87.2 & 122.6 & 191.2 & 86.0 & 117.3 & 175.0 & 85.2 & 114.3 & 161.1 \\
\hline $\mathrm{CO}$ : Coal mining & 2.1 & 2.7 & 4.0 & 2.0 & 2.6 & 3.6 & 2.0 & 2.4 & 3.1 \\
\hline PG: Crude petroleum, gas & 1.4 & 2.1 & 3.6 & 1.4 & 2.0 & 3.3 & 1.1 & 1.6 & 2.6 \\
\hline PA: Paper and paper products & 5.3 & 7.7 & 12.5 & 5.2 & 7.3 & 11.4 & 5.1 & 7.1 & 10.4 \\
\hline RP: Refined petroleum products & 27.7 & 39.9 & 65.0 & 27.3 & 38.2 & 59.5 & 19.0 & 25.8 & 37.6 \\
\hline CE: Cement production & 6.0 & 8.5 & 13.7 & 5.9 & 8.2 & 12.5 & 5.6 & 7.4 & 10.5 \\
\hline IS: Iron and steel & 17.3 & 26.8 & 47.5 & 17.1 & 25.6 & 43.3 & 15.7 & 22.5 & 34.7 \\
\hline EL: Electricity production & 11.9 & 16.3 & 25.3 & 11.7 & 15.6 & 23.1 & 9.9 & 12.6 & 16.9 \\
\hline TR: Transport services & 85.4 & 123.2 & 199.2 & 84.2 & 117.9 & 182.6 & 77.5 & 106.6 & 155.7 \\
\hline OE: Other economy & 495.8 & 680.0 & 1058.4 & 488.7 & 648.9 & 963.1 & 478.3 & 609.1 & 828.3 \\
\hline
\end{tabular}

Source: Authors' computations. 
reduction in agriculture (AG) is around $7.5 \%$ on average whereas it reaches to $16.5 \%$ in iron and steel industry (IS), $22.9 \%$ in electricity production (EL), $24.8 \%$ in petroleum and gas (PG) and $35.7 \%$ in refined petroleum production (RP) sectors. Then again, the largest savings from $\mathrm{CO}_{2}$ emissions also take place in these sectors. The overall emission reduction reaches to $53 \%$ in coal mining (CO) and $23.2 \%$ in iron and steel (IS) by 2020. Note that the proportions of output and $\mathrm{CO}_{2}$ emissions reductions are not comparable in a linear fashion, since both variables depend on the substitution possibilities of both energy inputs in production among themselves and with the other inputs as well.

The scenario under foreign aid has no direct effect on output/investment/input demand decisions of the production sectors, yet by offering funds to finance abatement investments, generates a proportional decrease in the sectoral $\mathrm{CO}_{2}$ emissions of the economy.

\section{Conclusion}

In this paper, we utilize a computable general equilibrium model for Turkey to study the economic impacts of the intended policy scenarios of compliance with the Kyoto Protocol. Turkey is the only country that appears in the Annex-I list of the Rio Summit and yet an official target for $\mathrm{CO}_{2}$ emission reductions has still not been established. Thus, as part of its accession negotiations with the EU, it will likely to face significant pressures to introduce its national plan on climate change along with specific emission targets and the associated abatement policies. Given this motivation, we report on the general equilibrium effects of various possible environmental abatement policies in Turkey over the period 2006-2020.

Several policy conclusions emerge from our analysis:

- Our modeling results suggest that the burden of possible imposition of direct carbon emission quotas would be quite high. This burden will necessitate a significant tax imposition on the producers to enforce the $\mathrm{CO}_{2}$ quotas. According to our results, imposition of $\mathrm{CO}_{2}$ quota at $60 \%$ level to the base-run calls for a carbon tax of 20-15\% over 2006-2020. The GDP loss incurred under this scenario is above $30 \%$ as of 2020 .

- Such a tax burden will likely lead to tax evasion practices, and will encourage the underground (informal) economy. Thus, it will likely lead to increased informalization of the production activities. The already high levels of producer tax incidences reduce the effectiveness of additional carbon taxation opportunities significantly.

- In contrast to a direct " $\mathrm{CO}_{2}$ quota-cum-carbon tax" policy, taxation of energy use in sectoral production seems to produce viable results. In returns to a $20 \%$ energy tax for producers, aggregate $\mathrm{CO}_{2}$ emissions are reduced by $25.8 \%$ with a loss of GDP of $8.8 \%$ by the end of 2020. The energy taxation policy suffers strongly, however, from its very adverse employment effects. Unemployment rates rise significantly as a result of the introduced energy taxes. With limited substitution possibilities in input mix among labor and energy inputs, producers are bound to cut back labor employment as they are faced with increased energy costs.

- The taxation policies suggest very clearly that possible interventions of new environmental taxes would have adverse outcomes either on employment or on sectoral output levels directly. A more effective policy would necessarily call for a simultaneous reduction on the existing tax burden on producers elsewhere together with introduction of environmental taxes. A reduction of employment taxes can be implemented along with the imposition of energy tax use. Such a policy would be conducive in attaining $\mathrm{CO}_{2}$ abatement targets together with employment 
incentives. Various studies show that using such tax revenues to finance reductions in the already existing (and mostly distortionary) taxes on employment, production, or sales can achieve superior outcomes with attaining environmental targets at lower cost-perhaps even at a positive net gain (see for example, Goulder, Parry, Williams, \& Burtraw, 1999; Parry \& Oates, 2000; Parry, Williams, \& Goulder, 1999).

- Overall, however, a first-best environmental policy has to call for further incentives towards reducing energy intensities in production through more efficient production methods. By itself this is no easy task and certainly comes at significant investment cost. Modeling results suggest that leaving the burden of the abatement investments to production sectors alone create significantly adverse results in terms of overall economic performance. According to our results, abatement investments that amount to $1.5 \%$ of GDP annually call for $23 \%$ tax rate on energy (primary and secondary) input usage.

- Further indirect taxes on the production sectors would likely trigger unfavorable dynamics in production and employment. Parallel to the reduction in output, one observes adverse outcomes on already high unemployment rates of the economy.

- The advantageous environment likely to be produced by foreign aid on abatement investments displays high economic growth attained together with reductions in $\mathrm{CO}_{2}$ emissions. An annual flow of foreign aid/credit of $1.5 \%$ as a ratio to the GDP designed to cover the costs of abatement investments for adoption of the "best available technologies" help reduce Turkish $\mathrm{CO}_{2}$ emissions by $4.9 \%$ in 2020 and by a cumulative of 199.1 million tonnes over the whole analyzed period. By way of a caveat, it should be clear that designing such an international aid/credit system for the developing countries in their efforts towards abatement investments is by no means an easy task, and one should be aware that international coordination and cooperation, although crucial, could be difficult to achieve. The Protocol, as an international attempt itself, has been criticized for defining mechanisms that are too bureaucratic and cumbersome. Aldy, Barett, \& Stavins (2003), for instance, point out to ambiguities in the existing institutional framework at the global scale, and identify more than a dozen competing approaches with regard to international carbon taxation and international technology standards.

- A second caveat concerns the boundaries of our modeling paradigm. The CGE model is a technical laboratory device where the adjustment path as characterized by the simulation exercises reflects a "well-defined" and "smooth" general equilibrium system, based on consumer and producer optimization in the absence of any rigidities and/or structural bottlenecks. Thus, the adjustments of the model economy in response to various policy shocks should not be taken as a measure of the global stability properties of the real economy, but rather as a direct outcome of the laboratory characteristics of a set of macroeconomic simulations. For these reasons, our results should at best be regarded as approximations of the long-run equilibrium effects of environmental and investment policies on production, employment, current account, capital accumulation and consumer welfare.

- Finally, it should be noted that the model fails to identify the welfare benefits and possible productivity gains from reduced $\mathrm{CO}_{2}$ emissions. Reductions in gaseous pollutants, for instance, are likely to lead to improved health conditions, enabling increases in labor productivity. Likewise, reductions in gaseous emissions would likely lead to further productivity gains in, say agriculture and food availability, due to improved climatic conditions. In the absence of detailed cost-benefit analysis of reducing $\mathrm{CO}_{2}$ emissions on a microlevel, we had to abstain from making ad hoc assumptions on such favorable external incidence of abatement investments. 


\section{Acknowledgements}

Project support for this study was provided by the Government of Turkey and the United Nations Development Program on Economic Evaluation for Policy Making under the UNDP-GEF Project: "Enabling Activities For The Preparation Of Turkey's Initial National Communication To The UNFCCC" prepared for UNDP and the Ministry of Environment and Forestry, Republic of Turkey. The authors gratefully acknowledge the diligent research assistance of Bengisu Vural and Çağaçan Değer, and the invaluable suggestions provided by Bill Gibson, Yasemin Örücü, Katalin Zaim and by the "Climate Change Team" of the Ministry, headed by Ms. Günay Apak.

\section{References}

Adkins, L. G., \& Garbaccio, R. F. (1999). A bibliography of CGE models applied to environmental issues. Mimeo: US Environmental Protection Agency, Office of Policy, Office of Economy and Environment.

Agénor, P. R., Jensen, H. T., Verghis, M., \& Yeldan, E. (2007). Disinflation, fiscal sustainability, and labor market adjustment in Turkey (Chapter 7). In A. Richard, A. Izquierdo, \& H. T. Jensen (Eds.), Adjustment policies, poverty and unemployment: The IMMPA framework. Blackwell Publishing/Oxford University Press.

Aldy, J. E., Barett, S., \& Stavins, R. N. (2003). Thirteen plus one: A comparison of alternative climate policy architectures. Climate Policy, 3(4), 373-397.

Boratav, K., Türel, O., \& Yeldan, E. (1996). Dilemmas of structural adjustment and environmental policies under instability: Post-1980 Turkey. World Development, 24(2), 373-393.

Ediger, V. Ş., \& Huvaz, Ö. (2006). Examining the sectoral energy use in Turkish economy (1980-2001) with the help of decomposition analysis. Energy Conservation and Management, 47, 732-745.

Ercan, H. \& Tansel, A. (2006). How to approach the challenge of reconciling labor flexibility with job security and social cohesion in Turkey. Paper of the Turkish expert group's preparation for European Council's FORUM 2005. Strasbourg.

Goulder, L., Parry, I., Williams, R., \& Burtraw, D. (1999). The cost effectiveness of alternative instruments for environmental protection in a second-best setting. Journal of Public Economics, 72(3), 329-360.

Goulder, L. \& Pizer, W. (2006). The economics of climate change. NBER working paper no. 11923. http://www.nber.org/papers/w11923.

International Energy Agency (2005, February). Industrial competitiveness under the European Union emissions trading scheme. IAE Information Paper.

Karakaya, E., \& Özçağ, M. (2001). Sürdürülebilir Kalkınma ve İklim Değişikliği: Uygulanabilecek İktisadi Araçların Analizi. In First conference and fiscal policy in transition economies

Kumbaroğlu, S. G. (2003). Environmental taxation and economic effects: A computable general equilibrium analysis for Turkey. Journal of Policy Modeling, 25, 795-810.

Lise, W. (2006). Decomposition of $\mathrm{CO}_{2}$ emissions over 1980-2003 in Turkey. Energy Policy, 34, 1841-1852.

OECD (2004). Economic survey: Turkey. http://www.oecd.org/dataoecd/42/47/33821199.pdf.

Parry, I., \& Oates, W. (2000). Policy analysis in the presence of distorting taxes. Journal of Policy Analysis and Management, 19, 603-614.

Parry, I., Williams, R. R., \& Goulder, L. (1999). When can carbon abatement policies increase welfare? The fundamental role of distorted factor markets. Journal of Environmental Economics and Management, 37(1), 52-84.

Roe, T. L., \& Yeldan, E. (1996). How doctor's prescriptions may fail: Environmental policy analysis under alternative market structures. METU Studies in Development, 23(4), 577-600.

Sahin, S. (2004). An economic policy discussion of the GHG emission problem in Turkey from a sustainable development perspective within a regional general equilibrium model: TURCO. Sorbonne: Université Paris I Panthéon.

Telli, C., Voyvoda, E., \& Yeldan, E. (in press). Modeling general equilibrium for socially responsible macroeconomics: Seeking for the alternatives to fight jobless growth in Turkey. METU Studies in Development.

Tunal1, I. (2003). Background study on the labour market and employment in Turkey. Prepared for the European Training Foundation.

Tunç, G. I., Türüt-Aşık, S., \& Akbostancı, E. (2006). $\mathrm{CO}_{2}$ emissions vs. $\mathrm{CO}_{2}$ responsibility: An input-output approach for the Turkish economy. ERC Working Paper, No. 06/04.

UNDP \& World Bank (2003). Energy and environment review: Synthesis report Turkey, Washington, ESM273, $273 / 03$. Energy Sector Management Assistant Programme. 